\title{
El eventual legado de Mariátegui en la composición ideológica de Sendero Luminoso
}

\section{The Eventual Legacy of Mariátegui in the Ideological Composition of Shining Path}

\author{
Mariano García de las Heras González ${ }^{1}$ \\ Universidad Complutense de Madrid (España)
}

Recibido: 11-06-19

Aprobado: 06-03-20

\section{Resumen}

La figura de José Carlos Mariátegui es una referencia intelectual en el pensamiento revolucionario latinoamericano. $\mathrm{Su}$ producción intelectual está acompañada de un compromiso político con las ideas transformadoras aplicadas al conjunto de América Latina y, de manera especial, a Perú. Sus aportaciones teóricas y sus propuestas prácticas para organizar a la clase obrera del país andino son motivo de disputa ideológica en el seno del comunismo peruano durante las décadas centrales del siglo XX. En ese ambiente surge Sendero Luminoso, una organización dispuesta a impulsar el proceso revolucionario por la vía armada. Este texto busca los anclajes de su ideario a partir de los planteamientos iniciales sugeridos por el autor de Siete ensayos de interpretación de la realidad peruana.

Palabras-clave: Mariátegui, Abimael Guzmán, Sendero Luminoso, Perú, comunismo peruano, procesos revolucionarios.

\footnotetext{
${ }^{1}$ (mgarciadelasheras@ucm.es) Historiador y politólogo. Actualmente cursa el programa de doctorado en Ciencias Políticas en la Universidad Complutense de Madrid con una beca del Ministerio de Educación. Secretario de Redacción en Geopolítica(s). Revista de estudios sobre espacio y poder. Sus últimas publicaciones son: "La impunidad de la dictadura franquista". Reflexión Política, 21(43), 2019, pp. 36-48. y "Experiencias sobre el terrorismo de estado en Perú (1980-2000). Revista Universitaria de Historia Militar, 8(17), 2019, pp. 71-96.

ORCID: https://orcid.org/0000-0001-5978-2156.
} 


\begin{abstract}
José Carlos Mariátegui is an intellectual reference in Latin American revolutionary thought. His intellectual production is accompanied by a political commitment to revolutionary ideas applied to Latin America as a whole and, especially, to Peru. His theoretical contributions and his practical proposals to organize the working class of the Andean country are reason for ideological discussion within Peruvian Communism during the central decades of the 20th century. In this environment, Shining Path emerges, an organization willing to promote the revolutionary process by armed means. This text looks for the anchors of his ideology from the initial approaches suggested by the author of Seven essays of interpretation of the Peruvian reality.
\end{abstract}

Key-words: Mariátegui, Abimael Guzmán, Shining Path, Perú, Peruvian Communism, Revolutionary Processes.

\title{
1. Introducción
}

El pensamiento de José Carlos Mariátegui (1894-1930) es una referencia ineludible en el análisis marxista latinoamericano y su producción teórica constituye una radiografía minuciosa sobre el recorrido histórico de Perú hasta el primer tercio del siglo XX. Sin embargo, sus contribuciones no permanecen restringidas al ámbito intelectual y el encuadramiento de la clase obrera peruana es su máxima expresión, cuya finalidad radica en revertir la realidad del país andino. Su producción intelectual conjuga el pensamiento marxista con la escala geográfica estatal, que permite la elaboración de "una manera específica -peruana, indoamericana, andina- de pensar a Marx" (Flores, 1980: 12).

El legado de su propuestas políticas es objeto de disputa en los decenios centrales de la pasada centuria. En ese ambiente, el Partido Comunista del Perú (PCP) experimenta una serie de fraccionamientos que expresan, al mismo tiempo, las discrepancias ideológicas del comunismo en plena Guerra Fría. El nacimiento de la organización Sendero Luminoso está ubicado en esta coyuntura y su despliegue ideológico reclama, inicialmente, la doctrina mariateguiana.

La formación liderada por Abimael Guzmán (1934-) plantea la revolución como un fenómeno indiscutible para la transformación de la sociedad peruana y, de este modo, Sendero Luminoso adquiere un protagonismo relevante durante el último tercio del pasado siglo. Su apuesta por recurrir a la violencia con la pretensión de imponer un proceso revolucionario en Perú es el epítome de una creciente radicalización incubada durante una década.

El propósito de este texto consiste en valorar las aportaciones del amauta en la mentalidad revolucionaria de Sendero Luminoso. Las siguientes líneas 
exploran las formulaciones ideológicas comparadas entre Mariátegui y la organización senderista a partir de un triple eje: el diagnóstico de las condiciones socioeconómicas de Perú, la selección de los sujetos revolucionarios y, por último, el papel motivador de la violencia en la revolución. Los títulos firmados por el amauta de Siete ensayos de interpretación de la realidad peruana e Ideología y política son escrutados con algunas de las fuentes recopiladas por el Centro de Documentación de los Movimientos Armados para establecer, por un lado, las convergencias en sus formulaciones y, por otro, el distanciamiento en sus análisis marcados por la búsqueda de estimular un proceso revolucionario en Perú.

\section{Breve genealogía senderista}

En el universo comunista, la cristalización de la polémica sino-soviética en Perú es apreciable a través de la ramificación del Partido Comunista. Las formaciones escindidas añaden el título nominal de sus respectivos aparatos de difusión propagandística: el PCP-Unidad, que mantiene una línea convergente con las propuestas de Moscú, y el PCP-Bandera Roja, que muestra su afinidad con Pekín (Ríos, 2019). La configuración de la dirección intelectual de Sendero Luminoso remite a la Universidad Nacional de San Cristóbal de Huamanga (UNSCH), que comparte sede con el Comité Regional José Carlos Mariátegui del PCP y suministra "nuevos referentes políticos que tendían a cerrar la brecha generacional" (Degregori, 2011: 116).

Guzmán accede a la UNSCH en calidad de catedrático en filosofía y participa, durante los primeros años de la década de 1960, en las fricciones intestinas que desembocan en la escisión registrada en enero de 1964 para integrar el Comité Central del recientemente constituido PCP-BR. Un año más tarde, Guzmán viaja a China para recibir instrucción como cuadro político y durante su estancia descubre la figura de Mariátegui mediante el estudio del pensamiento maoísta. En su regreso al país andino, el filósofo arequipeño busca rescatar los planteamientos de Mariátegui y reconstituir el Partido Comunista desde una perspectiva basada en los principios maoístas. Las fuentes ideológicas que nutren la formación política que lidera Guzmán son evidenciadas del siguiente modo:

"Es la aplicación del marxismo-leninismo-maoísmo a la revolución peruana la que ha generado el pensamiento Gonzalo, en la lucha de clase de nuestro pueblo, del proletariado principalmente, de las incesantes luchas del campesinado [...] Éste fue antes pensamiento guía, y si hoy el Congreso ha sancionado pensamiento Gonzalo es porque se ha producido un salto en ese pensamiento guía, precisamente en el desarrollo de la Guerra Popular” (PCP-SL, 1970). 
El Comité Regional de Ayacucho del PCP-BR experimenta un notable crecimiento bajo el liderazgo de Guzmán entre los años 1964-1969. El principal foco de su actividad radica en la UNSCH, pero las continuas discrepancias políticas provocan una serie de fragmentaciones en el seno de Bandera Roja que culminan en el surgimiento del PCP-Sendero Luminoso a comienzos de 1970 (Ríos y Sánchez, 2018). Algunos autores trazan una equiparación con el proceso revolucionario chino para señalar la configuración de un "Yenán andino" (Degregori, 2000, 2012; Rénique, 2003).

Guzmán encabeza, en el año 1974, una nueva escisión que será célebremente conocida por el lema exhibido en su periódico: "Por el Sendero Luminoso de José Carlos Mariátegui" (Ríos y Sánchez, 2018). En términos estrictamente ideológicos, la idea de recuperar el pensamiento mariateguiano implica sintetizar las aportaciones del revolucionario chino con las formulaciones del escritor peruano, ya que representan "la expresión política culminante del proletariado peruano" (PCP-SL, 1975). El filósofo arequipeño reclama para la nueva formación comunista "el blasón de ser el auténtico partido marxista fundado en los años veinte, destinado a ser el instrumento decisivo en el proceso revolucionario en el Perú" (Manrique, 2007: 7).

Por último, las variaciones en las nomenclaturas señalan la disputa por el fundamento científico con el propósito de certificar unas garantías en el triunfo final de la revolución. La apariencia rigurosa procedente de un método científicamente probado aporta las justificaciones de sus procedimientos y encauza las discrepancias ideológicas. Sendero Luminoso proclama, en este sentido, que "el camino de Mariátegui tiene un eje: el Partido Comunista" (PCP-SL, 1975).

\section{Anclajes socioeconómicos: condición colonial y pervivencia feudal}

Mariátegui afronta la problemática de Perú tras su periplo europeo a través de una triple polémica con los ideólogos del orden oligárquico al servicio del imperialismo, el nacionalismo democrático aprista y la dirección oficial de la III Internacional en su sección latinoamericana (Quijano, 2014: 395). La sustancia de su producción literaria sobre las contrariedades del país andino está, aunque con implicaciones sobre América Latina en su conjunto, en su obra titulada Siete ensayos de interpretación de la realidad peruana y su trabajo Ideología y política $^{2}$ (Quijano, 2014: 394).

El encaje de la trayectoria descrita por Perú en el orden mundial implantado en los albores del siglo XX significa, en virtud de la caracterización de ambas

${ }^{2}$ El citado estudio es el libro más leído en la historia de Perú y su autor es la figura más relevante del pensamiento marxista en América Latina (Degregori, 2011: 133-134, n. 19)

Araucaria. Revista Iberoamericana de Filosofia, Politica, Humanidades y Relaciones Internacionales, año $22, \mathrm{n}^{\circ} 43$. Primer semestre de 2020. Pp. 393-417. ISSN 1575-6823 e-ISSN 2340-2199 https://dx.doi.org/10.12795/araucaria.2020.i43.20 
realidades, el predomino decisivo de la escala global para determinar el rumbo durante las décadas siguientes a pesar de las tentativas por reconfigurar la estructura social peruana dañada tras los efectos provocados por la derrota ante Chile en la Guerra del Pacífico (Quijano, 2014). El resultado es la persistencia de dos focos históricos que proyectan la imagen de una explotación perenne: colonialismo y feudalismo.

La entidad estatal permanece sometida a un proceso de reconfiguración bajo los designios del capital monopolista, como expresión del imperialismo, y su caracterización está precisada por dos cuestiones elementales: la indefinición nacional provocada por el carácter semicolonial que asume la burguesía dirigente y la indeterminación de clase motivada por la articulación de unos intereses oligárquicos (Quijano, 2014: 345). La convergencia entre el sujeto revolucionario y el pensamiento de Mariátegui representa un indicio para inscribir la fuerza motriz que representa la lucha de clases en un contexto definido "por la depuración y la profundización del carácter histórico de la sociedad peruana y de la madurez de clase de su proletariado" (Quijano, 2014: 333).

Mariátegui dedica varios pasajes de su obra al análisis de la situación económica de Perú y subraya que, tras un amplio recorrido histórico, la Guerra del Pacífico es un hito en la caracterización de la economía del país andino. La derrota frente a Chile provoca un colapso de las fuerzas productoras evidenciado en la pérdida de sus principales fuentes -guano y salitre-, la depresión generalizada del comercio, el estancamiento de la producción, la depreciación monetaria y la quiebra del crédito exterior (Mariátegui, 2007).

El caudillismo militar retoma las riendas del poder a pesar de su incapacidad para abanderar una adecuada reconstrucción económica, si bien la incipiente burguesía capitalista logra asumir determinadas funciones políticas que devienen en una reorganización de la economía peruana acomodada a unos intereses de clase muy específicos. En su explicación, Mariátegui añade:

\footnotetext{
"La revolución americana, en vez del conflicto entre la nobleza terrateniente y la burguesía comerciante, produjo en muchos casos su colaboración, ya por la impregnación de ideas liberales que acusaba la aristocracia, ya porque ésta en muchos casos no veía en esa revolución sino un movimiento de emancipación de la corona de España" (2007: 54).
}

Mariátegui (2007) recurre al ejemplo de la solución aportada al problema monetario, que responde a unos criterios exclusivamente beneficiosos para los sectores latifundistas, y expresa la instrumentalización estatal en la configuración de una sociedad burguesa siguiendo la idea de que "el gobierno del Estado moderno no es más que una junta que administra los negocios comunes de toda la clase burguesa" (Marx y Engels, 1997: 13). 
Perú experimenta un proceso acelerado de incorporación al sistemamundo capitalista tras la Primera Guerra Mundial y su principal resultado es "un reforzamiento de la hegemonía de la costa en la economía peruana" (Mariátegui 2007: 19). En consecuencia, Mariátegui verifica el desarrollo "de una clase capitalista, dentro de la cual cesa de prevalecer como antes la antigua aristocracia [...] Se constata el robustecimiento de la burguesía" (ibídem).

El imperialismo monopolista como fase capitalista recurre al poder emanado de las relaciones feudales porque manifiesta su consideración por la clase dominante en términos políticos, aunque sus intereses económicos muestran severas discrepancias. La emergencia de la titularidad individual de la tierra, la expropiación de los latifundios y la liquidación de los privilegios feudales no contradicen a corto plazo los intereses imperialistas (Mariátegui, 2010).

El amauta divisa un componente de clase en la lucha contra el imperialismo, que entronca con sus reflexiones sobre la variable racial para concluir con un razonamiento ajustado al espacio exclusivamente latinoamericano. Una prueba de ello es el documento epistolar redactado por el Grupo de Lima en 1929 y que señala lo siguiente:

"La colaboración con la burguesía, y aun de muchos elementos feudales, en la lucha antiimperialista china, se explica por razones de raza, de civilización nacional que entre nosotros no existen [...] En Indoamérica las circunstancias no son las mismas. La aristocracia y la burguesía criollas no se sienten solidarizadas con el pueblo por el lazo de una historia y de una cultura comunes. En el Perú, el aristócrata y el burgués blancos, desprecian lo popular, lo nacional. Se sienten, ante todo, blancos [...] El factor nacionalista, por estas razones objetivas que a ninguno de ustedes escapa seguramente, no es decisivo ni fundamental en la lucha antiimperialista en nuestro medio" (Mariátegui, 2010:119)

Mariátegui subraya, frente a las explicaciones de Haya de la Torre ${ }^{3}$ y de las tendencias apristas, el contenido de clase implícito en el imperialismo y resta importancia a las cuestiones de orden nacional. El amauta manifiesta, en la I Conferencia Comunista Latinoamericana celebrada en la ciudad de Buenos Aires durante el mes de junio del año 1929, que:

"El antiimperialismo, para nosotros, no constituye ni puede constituir, por sí solo, un programa político, un movimiento de masas apto para la conquista del poder. El antiimperialismo, admitido que pudiese movilizar al lado de las masas obreras y campesinas, a la burguesía y pequeña burguesía nacionalistas [...] no anula el antagonismo entre las clases, no suprime su diferencia de intereses" (Mariátegui, 2010: 120)

\footnotetext{
${ }^{3}$ El dirigente del APRA sostiene que el imperialismo implica en América Latina la constitución de una dualidad histórica entre el capitalismo y el feudalismo. Por el contrario, Mariátegui no contempla esa tesis porque considera que el imperialismo representa, especialmente, un capitalismo monopolista en proceso de expansión a escala mundial.
} 
Las contribuciones de Mariátegui a la reflexión sobre la articulación de la lucha revolucionaria añaden un matiz en la escala continental, que marca las diferencias ente los países meridionales y las entidades estatales mesoamericanas. El antiimperialismo no puede constituir, a diferencia de la concepción aprista, un programa político o un movimiento de masas apto para la conquista del poder porque su lucha no anula la dialéctica de clases. En gran medida, los esfuerzos del amauta radican en la explicación y la demostración de que la única solución para frenar la creciente fuerza imperialista es la revolución socialista, aunque sin prescindir de los elementos potencialmente movilizadores que concurren en esta disputa (Mariátegui, 2010).

En su argumentación, Mariátegui esquematiza el desarrollo económico peruano para su progresiva incorporación a la lógica que domina la economíamundo, según el vocabulario braudeliano. Las primeras etapas reflejan el establecimiento de unas pautas que marcan el compás de la industrialización moderna y dotan a su funcionamiento de un dinamismo favorecido por la volatilidad del capital financiero. El ascenso de Estados Unidos como potencia imperial en franca competición con el poder británico simboliza una fase transitoria, que incluye a Perú en los circuitos de dependencia comercial con Washington. Los vestigios de la condición colonial no son eliminados, sino que son sustituidos como consecuencia de la permuta en la ubicación del enclave metropolitano: la Casa Blanca ocupa el sitio de la Corona hispánica.

Uno de los principales efectos de esta dilatada etapa histórica consiste en la consolidación de una burguesía capitalista con aspiraciones a colonizar el poder político. Los aspectos destacados en el recorrido económico descrito por Mariátegui anticipan los dos pilares que sostienen su interpretación de la realidad peruana: el semifeudalismo y la semicolonialidad. El pensador natural de Moquegua detalla estas circunstancias en los siguientes términos: "Pesan sobre el propietario criollo la herencia y educación españolas, que lo
impiden percibir y entender netamente todo lo que distingue al capitalismo de
la feudalidad. Los elementos morales, políticos, psicológicos del capitalismo no
parecen haber encontrado aquí su clima. El capitalista, o mejor el propietario,
tiene el concepto de la renta antes que el de la producción" (Mariátegui, 2007:
24-25)

La existencia de estas relaciones feudales obedece a la pervivencia de la gran propiedad. En Perú, según las observaciones del amauta, la formación de un modo de producción capitalista descansa sobre la negación de la concepción burguesa; es decir, el espíritu del feudo (Mariátegui, 2007). El autor de Siete ensayos concluye que una economía capitalista representa un fenómeno urbano alimentado por la libre actividad del campesinado y exige, por tanto, una profunda reestructuración del medio rural para desencadenar un proceso 
revolucionario porque "sobre una economía semifeudal no pueden prosperar ni funcionar instituciones democráticas y liberales" (Mariátegui, 2007: 42).

La continuidad del feudalismo tiene su máxima expresión en la organización latifundista y las prácticas de servidumbre, que dominan las relaciones sociales de producción. En efecto, Mariátegui sostiene la siguiente tesis: la liquidación de las formas serviles que estrangulan a la población indígena requiere la eliminación del latifundio porque "no renegamos, propiamente, la herencia española; renegamos la herencia feudal" (Mariátegui, 2007: 42).

La explotación del campesinado por el predominio terrateniente significa la vertebración de un conjunto sistémico que desborda el poder local e instala su influencia a escala regional. El principal resultado de esta dinámica es la provisión de gobernabilidad porque permite a las instituciones estatales controlar el poder político mediante la articulación del caciquismo y el gamonalismo (Quijano, 2014). El razonamiento de Mariátegui indica que el propósito esencial radica en la anulación del modelo productivo feudal apoyado en el gamonalismo, el latifundismo y la servidumbre. El amauta puntualiza esta idea del siguiente modo:

\begin{abstract}
"Verdaderamente, no creo que se pueda afirmar que el carácter del colectivismo primitivo ha sido el de evolucionar a la propiedad privada, cuando las comunidades, que han seguido siendo atacadas y fragmentadas por todas partes, por un siglo más de explotación burguesa republicana, subsisten en un número tan grande y asoman su cuerpo vigoroso y siempre joven a los albores de una nueva etapa colectivista" (Mariátegui, 2010: 98).
\end{abstract}

La cuestión agraria equivale al problema de la liquidación del feudalismo en el país andino e informa de una tarea incompleta en el procedimiento político del sistema democrático-burgués. En esta dirección, las medidas desamortizadoras relativas a la propiedad agrícola no conducen al desarrollo del fraccionamiento de la tierra y su principal resultado suscribe la pervivencia del predominio de la clase terrateniente en Perú. En la etapa republicana,

\footnotetext{
"la nueva clase gobernante, ávida y sedienta de riquezas, se dedica a agrandar sus latifundios a costa de las tierras pertenecientes a la comunidad indígena, hasta llegar a hacerlas desaparecer en algunos departamentos. Habiéndoseles arrebatado la tierra que poseían en común todas las familias integrantes del ayllu ${ }^{4}$, éstas han sido obligadas, a buscar trabajo, dedicándose al yanaconazgo (parceleros) y a peones de los latifundistas que violentamente los despojaron" (Mariátegui, 2010: 99-100)
}

\footnotetext{
${ }^{4}$ El término ayllu designa la agrupación comunitaria y familiar que actúa como núcleo social en la cultura incaica.
} 
Las variables introducidas por el pensamiento mariateguiano sobre el imperialismo permiten la comprensión de la naturaleza y el movimiento histórico concreto de las luchas de clases en el espacio latinoamericano (Quijano, 2007: LXXXIX). La vigencia de estos comportamientos proviene de la coyuntura definida por los procesos independentistas registrados en el primer tercio del siglo XIX y, en el caso concreto de Perú, en la rígida configuración de una clase burguesa que manifiesta "la convivencia de 'comunidad' y latifundio en el Perú está, pues, perfectamente explicada, no sólo por las características del régimen del Coloniaje, sino también por la experiencia de la Europa feudal" (Mariátegui, 2007: 52).

Las formulaciones elaboradas por Mariátegui en la década de los años veinte mantienen su vigencia inalterable, según Guzmán, medio siglo después (Manrique, 2007). Las reiteradas referencias a la condición semifeudal de la sociedad peruana sustentan la aplicabilidad en Perú del modelo maoísta, "aunque la apreciación senderista sostiene que 'las contradicciones son más agudas en el interior que en la capital" " (Rénique, 2003: 46; Degregori, 2011: 177). La politización de estas incompatibilidades condensa, según Mariátegui, las posibilidades revolucionarias en el país andino a través del potencial emancipador de la movilización campesina (PCP-SL, 1968).

En estas circunstancias, la principal tarea consiste en trasladar la doctrina del proletariado enunciada por el marxismo-leninismo a los segmentos agrarios y la escisión de Sendero Luminoso de la rama afín a la línea china - es decir, Bandera Roja- significa un hito fundamental en la gestación senderista (Rénique, 2003; Ríos y Sánchez, 2018).

En la cosmovisión senderista, el imperialismo simboliza el antagonismo de la emancipación de los pueblos y expresa el dique reaccionario frente a la revolución. En sintonía con el Partido Comunista de China, Sendero Luminoso considera que Moscú ha asumido una concepción social-imperialista y constituye, del mismo modo que Washington, un obstáculo en el rumbo revolucionario (Manrique, 2007).

\section{Los sujetos del proceso revolucionario}

La intensa búsqueda de fórmulas revolucionarias está condicionada por las sucesivas derrotas de los movimientos revolucionarios tras la exitosa experiencia cubana registrada en 1959. Sin embargo, como apunta Quijano (2014), el ciclo movilizador está asistido por el despertar de las protestas ancladas en el motor de la lucha de clases en algunos países del espacio latinoamericano-Bolivia, Chile, Colombia, Ecuador, Perú-, que pretenden reorientar las medidas introducidas por los gobiernos reformistas en favor de sus reivindicaciones. 
En Perú, las luchas campesinas que reivindican la titularidad de la propiedad de la tierra están inspiradas por el pensamiento de Mariátegui y su acción colectiva está orientada por el Partido Comunista. La reforma agraria aprobada en 1969 está motivada por los distintos ciclos de protestas, que reclaman la eliminación del gamonalismo como fuente originaria de las relaciones feudales vigentes en el país andino. La lucha de clases es una constante ineludible en el discurso senderista, que proclama la reivindicación de organizar la insurgencia ante el "clamor" de las masas y activar su movilización para iniciar la lucha armada (PCP-SL, 1980). Estas iniciativas conectan con la propuesta de Marx, que aparece señalada en el documento correspondiente a la II sesión plenaria del Comité Central: "los revolucionarios tienen por obligación profesional organizar la miseria para derrumbar el viejo orden" (PCP-SL, 1980).

Sendero Luminoso logra vertebrar una doctrina coherente y una sólida estructura organizativa, aunque su participación en las campañas movilizadoras registradas en la segunda mitad de la década de 1960 es prácticamente inexistente, ya que la elite senderista considera que las acciones colectivas responden al impulso de otros grupos de izquierdas que están "al servicio del social imperialismo soviético" (Degregori, 2000: 496). Además, los contornos del sistema político responden a unos intereses de clase particulares, que excluyen la participación de los sectores campesinos y de los segmentos de un proletariado incipiente como producto de las lógicas capitalistas asumidas por la economía peruana. De esta manera, los poderes ejecutivos albergados en la institución estatal confirman su carácter oligárquico (Quijano, 2014).

Los indicadores relativos a la estratificación social constituyen el factor decisivo en el análisis de América del Sur y, por tanto, la creación de partidos de clase y las organizaciones sindicales no muestran un desarrollo similar en tales latitudes. Ahora bien, los llamamientos procedentes de vagas fórmulas populistas no aportan soluciones transformadoras porque enmascaran “tendencias reaccionarias" (Mariátegui, 2010: 121).

La principal aportación política del amauta consiste en dotar al movimiento indígena de una concepción revolucionaria y emancipadora mediante la percepción de un horizonte basado en el proyecto revolucionario socialista. Mariátegui plantea la necesidad de anclar el movimiento del proletariado indígena a la fuerza motriz que impulsa la historia en la teoría marxista y subraya que "es imprescindible dar al movimiento del proletariado [...] un carácter neto de lucha de clases" (2010: 82). Su tesis apela a las relaciones sociales de producción y añade el potencial cuantitativo para activar la revolución:

"La nueva generación peruana siente y sabe que el progreso del Perú será ficticio, o por lo menos no será peruano, mientras no constituya la obra y no signifique el bienestar de la masa peruana que en sus cuatro quintas partes es indígena y campesina" (Mariátegui, 2007: 37) 
Mariátegui enfatiza la condición indígena de la población campesina, que no muestra una participación activa en la revolución. Por consiguiente, sus reivindicaciones están ausentes de un programa revolucionario que soslaya la cuestión agraria. Los fundamentos políticos de la República ordenan una tibia distribución de tierras para los segmentos indígenas, que impide solucionar la problemática latifundista y ataca las fórmulas comunales bajo el ideario liberal. En definitiva, el orden republicano de tono democrático-burgués inaugurado tras el proceso emancipador deteriora las condiciones del campesinado indígena (Mariátegui, 2007). En palabras de Rénique, la obra de Mariátegui opera "como texto fundamental de una propuesta socialista afincada en la comunidad indígena andina" (2003: 32).

El acento teórico depositado en la estructura económica adquiere una constante visibilidad en el análisis de Mariátegui, quien declara que "el régimen de la propiedad de la tierra determina el régimen político y administrativo de toda la nación" (2007: 42). En consecuencia, la cuestión agraria afecta al resto de las problemáticas larvadas en el país andino desde la formalización de su independencia.

La cuestión indígena es problematizada en su estudio sobre la realidad peruana porque "En Perú, los indios, según una estadística de 1920, han realizado el 98 por ciento de sus levantamientos por motivos ligados a la tierra" (Mariátegui, 2010: 106). En su examen sitúa la cuestión socioeconómica en un plano principal para sortear las prescripciones caracterizadas por un tono humanitario y filantrópico (Mariátegui, 2007: 39). Su análisis reclama, de modo categórico, el derecho del indio a la tierra y expresa el contenido materialista de sus fuentes ideológicas mediante el énfasis en las estructuras económicas. En su diagnóstico, Mariátegui asegura que "si la revolución hubiese sido un movimiento de las masas indígenas o hubiese representado sus reivindicaciones, habría tenido necesariamente una fisonomía agrarista" (Mariátegui, 2007: 53).

La subordinación del problema indígena a la cuestión de la propiedad es rotunda debido a la condición agrícola de los indios. Mariátegui insiste en la erosión de las tierras comunales incaicas debido a su paulatina sustitución por latifundios de titularidad individual, aunque mantienen la explotación indígena bajo un régimen feudal. Este proceso permanece inscrito en el curso histórico peruano a través del feudalismo y el absolutismo, que "transformaron poco a poco la organización comunal de los campesinos en instrumentos de explotación" (Mariátegui, 2007: 51). Los primeros indicios remiten a la época colonial porque "en el plano de la economía se percibe mejor que en ningún otro hasta qué punto la Conquista escinde la historia del Perú" (Mariátegui, 2007: 7). 
El indigenismo encarna una novedosa mentalidad y el discurso indigenista es enfatizado por Mariátegui con la pretensión de establecer una identificación cultural precisa con capacidad de alterar el legado colonial. Por esta razón, el amauta añade las reivindicaciones del indio al centro de sus planteamientos sobre el proceso revolucionario en el país andino. En sus propias palabras:

"En la América Latina, que encierra más de 100 millones de habitantes, la
mayoría de la población está constituida por indígenas y negros. Pero hay más:
¿cuál es la categoría social y económica de éstos? Los indígenas y negros están
en su gran mayoría, incluidos en la clase de obreros y campesinos explotados, y
forman la casi totalidad de la misma. Esta última circunstancia sería suficiente
para poner en plena luz toda la importancia de las razas en la América Latina,
como factor revolucionario" (Mariátegui, 2007: 89).

Mariátegui defiende, al mismo tiempo, las posiciones frentistas y un ejemplo nítido de ello es el texto publicado en El obrero textil con motivo de la celebración del 1 de mayo del año 1924. El escritor peruano reivindica la festividad de la citada fecha por su innegable contenido político, que expresa la unidad del proletariado revolucionario reunido en un frente único internacional y rescata la exhortación que cierra el Manifiesto Comunista firmado por Karl Marx y Friedrich Engels: "proletarios de los países, uníos". En su argumentación, el amauta expone las ventajas de la opción defendida en los siguientes términos:

\begin{abstract}
"no anula la personalidad, no anula la filiación de ninguno de los que lo componen [...] El programa del Frente Único considera exclusivamente la realidad inmediata [...] Preconizar el frente único no es, pues, preconizar la confusión ideológica [...] Todos deben sentirse unidos por la solidaridad de clase, vinculados por la lucha contra el adversario común, ligados por la misma voluntad revolucionaria, y la misma pasión renovadora. Formar un frente único es tener una actitud solidaria ante un problema concreto, ante una necesidad urgente" (Mariátegui, 2010: 136-137)
\end{abstract}

La pequeña burguesía es el grupo social más propensa para asumir la ascendencia de la mitología nacionalista. Sin embargo, como apunta Mariátegui, la cuestión fundamental consiste en la persistente oposición de la clase burguesa a la proletarización como consecuencia de una masa salarial muy reducida que impide, por tanto, la transformación operada en el posible ensanchamiento del proletariado (Mariátegui, 2010: 123). El autor de Siete ensayos finaliza su reflexión sobre las prácticas imperialistas con las siguientes palabras:

"En conclusión, somos antiimperialistas porque somos marxistas, porque somos revolucionarios, porque oponemos al capitalismo el socialismo como 
sistema antagónico, llamado a sucederlo, porque en la lucha contra los imperialismos extranjeros cumplimos nuestros deberes de solidaridad con las masas revolucionarias de Europa" (Mariátegui, 2010: 124).

En sus argumentaciones, Mariátegui concede un importante peso a la imagen de solidaridad para desarrollar el proceso revolucionario a través de la acción de clase:

"La conciencia de clase se traduce en solidaridad con todas las reivindicaciones fundamentales de la clase trabajadora. Y se traduce, además, en disciplina. No hay solidaridad sin disciplina. Ninguna gran obra humana es posible sin la mancomunidad" (Mariátegui, 2010: 143)

Mariátegui $(2007,2010)$ sostiene que el carácter colonial condiciona la vida económica de las repúblicas latinoamericanas. Esta circunstancia admite una tendencia creciente a medida que aumenta el desarrolla capitalista y, en consecuencia, la penetración imperialista. Las burguesías nacionales colaboran con el imperialismo mediante el control de las palancas del poder político y muestran, al mismo tiempo, una fuerte despreocupación por la soberanía.

La idea de soberanía conserva su efectividad debido a la impregnación de mitos y símbolos configurados en el contexto de las emancipaciones decimonónicas. Por esta razón, Mariátegui destaca que las expectativas desprendidas del posible desarrollo de un sentimiento nacionalista revolucionario entre la clase burguesa constituyen un profundo error. En discusiones libradas con los dirigentes apristas, que plantean una propuesta similar al nacionalismo chino del Kuomintang, Mariátegui subraya la necesidad de eludir las imitaciones europeas y sostiene que la acción revolucionaria debe responder a una apreciación exacta de la realidad latinoamericana (Mariátegui, 2010: 118).

La elite intelectual que impulsa el nacimiento de Sendero Luminoso surge en un ambiente político marcado por el declive de las condiciones de semifeudalidad denunciadas por Mariátegui, la pervivencia del gamonalismo, la debilidad mercantil y unas intensas expectativas depositadas en la idea de progreso a través del estímulo propiciado por la educación (Degregori, 2012). De hecho, a finales de la década de 1960, el departamento ayacuchano es testigo de un ciclo movilizador que reclama el acceso gratuito a la enseñanza y su impacto en la región adquiere tanta magnitud que algunos autores equiparan a Ayacucho con una suerte de "Yenán andino" (Degregori, 2011, 2012; Rénique, 2003).

La reivindicación senderista que demanda la continuidad del rumbo marcado por Mariátegui busca el impulso de una respuesta insurgente estimulada desde los sectores campesinos. 
La implantación territorial de Sendero Luminoso está dominada por la situación de aislamiento que define a Ayacucho, un departamento ubicado en la zona centro-meridional de la sierra peruana (Ríos, 2019). Su maquinaria política suscribe el principio maoísta de la guerra popular prolongada como instrumento revolucionario en los países periféricos dominados por el feudalismo y la herencia colonial. A diferencia del resto de las formaciones de izquierdas, que apuestan por acudir a las masas, la organización liderada por Abimael Guzmán experimenta un repliegue sobre el foco universitario con la firme intención de profundizar en el estudio del marxismo (Degregori, 2012).

La figura de Mariátegui es ensalzada por Guzmán, que enfatiza la voluntad del fundador del Partido Comunista del Perú para "organizar la fuerza armada del campesinado" (PCP-SL, 1968). Sendero abandona el enclaustramiento universitario para construir los llamados organismos generados, que representan movimientos propios resultantes de la acción desarrollada por el proletariado en diversos frentes, tales como el Movimiento Juvenil Popular o el Movimiento de Campesinos Pobres. La adhesión de estos grupos a la línea marcada por el PCP reconoce, por un lado, la inspiración de Mariátegui en la organización de la clase obrera peruana y, por otro, la imposición del centralismo hegemónico de la escuadra comunista en las directivas estratégicas.

Las experiencias revolucionarias en China y Cuba reverberan en el país andino tras los ciclos movilizadores registrados durante la década de 1960 . El ciclo de protestas protagonizado por campesinos y militantes adscritos a diversas organizaciones de izquierdas reactiva los planteamientos de una revolución de base agraria. Ahora bien, las formaciones políticas constituidas en los años veinte representan una barrera para las iniciativas insurgentes procedentes de un efímero movimiento guerrillero integrado por comunistas y apristas.

Las acciones de estas guerrillas urbanas ocupan los años centrales de la década de $1960 \mathrm{y}$, al margen de su escaso éxito, su actividad transmite una fuerte carga simbólica. Estas tentativas radicales tienen su inspiración en el foquismo guevarista y el resultado negativo de sus operativos provoca una serie de discusiones teóricas en el ámbito comunista, que concluyen con el fraccionamiento y la afirmación de diversas familias ideológicas (Rénique, 2003).

El pensamiento maoísta ofrece una referencia ideológica con mayores grados de persuasión en virtud de las circunstancias del comunismo peruano que la doctrina formulada por Che Guevara porque "el maoísmo era la forma contemporánea del marxismo-leninismo para los países atrasados 'con inmensas masas campesinas y proporcionalmente reducidas clases obreras"” (Rénique, 2003: 42). Las contribuciones maoístas al contexto peruano son apreciables fundamentalmente en los centros educativos y los sindicatos de 
docentes. El interés que despierta el pensamiento revolucionario cristaliza en al terreno académico de las ciencias sociales mediante la denominada "revolución de los manuales" (Degregori, 2012).

Sendero invoca, en consecuencia, una serie de referencias ancladas en la historia contemporánea peruana con la intención de perfilar su estrategia basada en la guerra popular. La iniciativa guerrillera capitaneada por el alférez Vallejos en Jauja durante el año 1963 es una prueba de ello, mientras que el ciclo movilizador posterior protagonizado por el Movimiento de Izquierda Revolucionaria y el Ejército de Liberación Nacional añaden otros ejemplos manifestados en la composición del imaginario insurgente de la organización liderada por Guzmán (Manrique, 2007).

El golpe militar que acontece en 1968 y las sucesivas restauraciones ejecutadas por el gobierno presidido por el general Juan Velasco Alvarado buscan satisfacer las demandas procedentes de diversos sectores de la izquierda política peruana. La reforma agraria y la nacionalización de recursos naturales son dos ejemplos del citado reformismo.

La derrota de los movimientos revolucionarios ${ }^{5}$ permite la consolidación nuevamente del poder oligárquico a través del encadenamiento de unas dictaduras cívico-militares que provocan el virtual entierro del pensamiento de Mariátegui durante prácticamente tres decenios. La memoria política de la clase obrera permanece oscurecida debido al desplazamiento del pensamiento de Mariátegui de sus posiciones centrales en términos intelectuales.

Perú mantiene los condicionantes propios del feudalismo en los análisis senderistas. Su concepción resta valor a la transición democrática precedida de una Asamblea Constituyente prolongada entre los años 1978-1979, ya que este proceso apenas representa "la tercera reestructuración del estado terrateniente burocrático corporativo" (PCP-SL, 1978). La sistematización de la teoría revolucionaria elaborada por Mao capta la atención de Guzmán, que incluye sus tesis con objeto de establecer paralelismos entre la situación de Perú y el panorama internacional. El Comité Central del PCP rescata los análisis del dirigente chino sobre el fenómeno descolonizador registrado tras la Segunda Guerra Mundial. La formación comunista peruana reclama la necesidad de emancipación de los pueblos latinoamericanos con respecto al imperialismo estadounidense y recurre a las palabras del Gran Timonel para "tomar nuestro destino enteramente en nuestras propias manos" (Tse-Tung, 1976: 177).

El núcleo senderista traza un recorrido por el pensamiento maoísta y destaca sus contribuciones sobre los conceptos estratégicos y tácticos en la

\footnotetext{
${ }^{5}$ El fracaso político no está restringido exclusivamente a la clase obrera peruana, ya que el triunfo de las oligarquías también significa la capitulación de la dirección revolucionaria del proletariado y del socialismo revolucionario frente a la Alianza Popular Revolucionaria Americana (APRA)
} 
lucha incesante contra las fuerzas reaccionarias. Sendero Luminoso acude a los diagnósticos de Mao para justificar su linaje ideológico, que entronca con las analogías establecidas por el Presidente de la República Popular de China en relación con las aspiraciones imperialistas de la Casa Blanca y el Kremlin en su disputa por la hegemonía (PCP-SL, 1977).

Sendero considera que su línea revolucionaria está suficientemente elaborada en 1977 y la constitución de un núcleo de cuadros afianzado permite iniciar su particular "guerra popular" (Degregori, 2000: 497). El escenario político peruano está marcado por una coyuntura transicional que dificulta la adhesión a las iniciativas insurgentes defendidas por Guzmán, ya que el resto de las escuadras marxistas aceptan su incorporación al juego parlamentario mediante la competición electoral.

Sendero Luminoso interpreta que el análisis leninista es aplicable a Perú porque reúne las condiciones objetivas descritas por Lenin. Sin embargo, el núcleo senderista señala que esta cuestión suscita un profundo desconcierto en el país andino, ya que el ciclo movilizador de las masas es contemplado como el germen de la coyuntura revolucionaria "para soslayar la revolución, la toma del poder y, en último término, soslayar la violencia revolucionaria para ir tras los procesos electorales y difundir el cretinismo parlamentario" (PCPSL, 1979).

La lectura senderista admite similitudes entre el escenario peruano y el análisis de Lenin porque la situación revolucionaria contrasta con las condiciones subjetivas, que son evidenciadas por los indicadores de la clase social y la existencia de unos instrumentos capaces de convertir la coyuntura de crisis en revolución mediante el recurso de la violencia. En el caso particular de Perú, la lucha armada y la configuración de un frente único al ritmo impuesto por el Partido Comunista son las soluciones planteadas por Sendero para desarrollar la creciente protesta popular.

Los estados de emergencia decretados para frenar la lucha popular y el encauzamiento de un proceso revolucionario transmiten, por un lado, la condición dictatorial de la institución estatal mediante el reforzamiento del poder ejecutivo y, por otro, la fragilidad estructural motivada por los síntomas derivados del estancamiento social y económico. Las contradicciones implícitas en el constante proceso de reordenación de la vida pública peruana completan la escena trazada por el PCP, que sitúa la convocatoria electoral en el centro de su diagnóstico sobre el contexto de la transición destinada a sustituir a las Fuerzas Armadas instaladas en el poder durante más de una década.

Sendero conjuga las tesis leninistas y maoístas para su aplicación a la realidad peruana (PCP, 1979). En primer lugar, la existencia de las dos condiciones formuladas por Lenin sobre la coyuntura revolucionaria. En segundo lugar, la situación objetiva planteada por Mao sobre una base de antagonismos. En tercera 
instancia, la necesidad de discernir la fase de la revolución entre las etapas estacionaria o en curso. Y, por último, la afirmación concluyente de involucrar a Perú en una situación revolucionaria objetiva en desarrollo.

\section{El papel de la violencia como instrumento revolucionario}

Georges Sorel es una de las fuentes inspiradoras para el autor de Siete ensayos y, en concreto, el amauta adopta la idea del mito social como base de la acción revolucionaria de las multitudes frente al escepticismo detectado en los círculos intelectuales. En su obra Reflexiones sobre la violencia (1906), el filósofo francés propone la formación de un sindicalismo obrero preparado para destruir la sociedad burguesa y todas sus instituciones.

Los diagnósticos de Mariátegui identifican la situación del campesinado indígena en los procesos de acumulación originaria del capital, ya que "las mejores tierras de producción han pasado a poder de los terratenientes, pues la lucha por aquéllas en los departamentos del sur ha llegado hasta el extremo de eliminar al poseedor indígena por la violencia o masacrándolo" (Mariátegui, 2007: 70). Al mismo tiempo, sus reflexiones identifican el carácter de sujeto revolucionario procedente de una coyuntura violenta porque "las sublevaciones de indios han tenido como origen una violencia que los ha forzado incidentalmente a la revuelta contra una autoridad" (Mariátegui, 2010: 77).

Mariátegui defiende el indigenismo vanguardista y el nacionalismo revolucionario, mientras afirma su firme oposición al "reformismo mediocre, el del socialismo domesticado, el de la democracia farisea. Además, si la revolución exige violencia, autoridad, disciplina, estoy por la violencia, por la autoridad, por la disciplina. Las acepto, en bloque, con todos sus horrores, sin reservas cobardes" (Mariátegui, 2007: 329).

La implantación de sistemas democráticos en América Latina no implica necesariamente la disminución de violencias, como bien demuestran los casos de México o Colombia. Sin embargo, la afirmación de una "democratización de la violencia" en estos países es una idea impertinente porque profundización de la desigualdad -desempleo, pobreza, analfabetismo- revela unas condiciones estructurales propicias para comprender el grado de conflictividad social y su posible traducción en formas de lucha armada en diferentes localizaciones latinoamericanas (Krujit y Koonings, 2002).

La singularidad del caso peruano está señalada por la iniciativa de un grupo insurgente que recurre a la lucha armada en el contexto definido por la implantación de "un gobierno de civiles" (Krujit y Koonings, 2002: 42). La violencia de Sendero Luminoso es exacerbada porque considera contaminado todo aquello que no sea generado por el Partido y esta imagen incluye un 
amplio abanico de sectores sociales, políticos y económicos: comunidades campesinas, representantes municipales, asociaciones no gubernamentales, organizaciones sindicales adscritas a otras formaciones de izquierdas. La apología de la violencia y su idealización como herramienta transformadora anudan las consideraciones morales con las formulaciones "científicas", que provocan un llamamiento urgente -e incluso ineludible- para convertir la teoría en práctica (Portocarrero, 2015: 24).

La apreciación de la base semifeudal y la explotación procedente del imperialismo conceden un matiz democrático a los procesos transformadores detectados en la periferia de la economía-mundo capitalista. El pensamiento maoísta propone una idea de revolución para los países que no han logrado completar la etapa revolucionaria burguesa, ya que "una sola chispa puede incendiar la pradera" (Tse-Tung, 1968a: 125). La existencia de una situación revolucionaria en desarrollo reclama la construcción de unas herramientas aptas para la edificación de unas circunstancias subjetivas: Partido, frente único y lucha armada (PCP-SL, 1979). El Comité Central insiste en que el principal desafío en Perú consiste en iniciar la lucha armada para cumplir con la revolución democrática-nacional $\mathrm{y}$, por consiguiente, su tarea radica en desarrollar inmediatamente la "creciente protesta popular" (PCP-SL, 1979). La figura de Mao reverbera de manera constante en el hilo argumental senderista $\mathrm{y}$, en esta ocasión, sus reflexiones cierran el comunicado de una Conferencia Nacional celebrada a finales del año 1979 en los siguientes términos:

\footnotetext{
"La historia nos enseña que una línea política y una línea militar justas no surgen ni se desarrollan espontánea y apaciblemente, sino en la lucha. Estas líneas tienen que luchar contra el oportunismo [...] Sin combatir estas nocivas desviaciones que minan la revolución y la guerra revolucionaria, y sin superarlas completamente, es imposible establecer una línea correcta y lograr la victoria en una guerra revolucionaria" (Tse-Tung, 1968b: 209).
}

La transferencia del examen maoísta a Perú realizado por Sendero reside en la percepción de una situación objetiva en el país andino. Este argumento está expresado por una serie de contradicciones latentes que potencian el momento revolucionario (PCP-SL, 1979). En primer lugar, el desarrollo de unos antagonismos entre las fuerzas imperialistas localizados en la escena global. En segundo término, la antítesis declarada a través de unos gobernantes reaccionarios y una masa de contribuyentes en la escala estatal. En tercer lugar, la incompatibilidad registrada entre las fórmulas imperiales y las burguesías industriales de carácter nacional. Y, por último, la discrepancia revelada entre la clase burguesa y el proletariado.

La lucha de clases es una constante ineludible en el discurso senderista, que proclama la reivindicación de organizar la insurgencia ante el "clamor" 
de las masas y activar su movilización para iniciar la lucha armada (PCP-SL, 1980). En la II sesión plenaria del Comité Central, la agrupación senderista aprueba la militarización efectiva del Partido con la finalidad de "convertir el verbo en acción" (PCP-SL, 1980). El discurso de Sendero presenta el objetivo de comenzar la lucha armada como una tarea perentoria y urgente, ya que responde a metas establecidas en función de una triple naturaleza: clase, historia y pueblo.

Sendero anuncia un dilema situado en la atmósfera política peruana definida por las iniciativas de implantar un sistema democrático que obedece a los parámetros liberales: la existencia o no de una coyuntura revolucionaria en Perú. Las prescripciones ancladas en el análisis marxista suscriben la objetividad de una revolución en curso y, por tanto, las líneas estratégicas del Partido consideran la tensión derivada de la dualidad entre revolución y contrarrevolución.

La trilogía compuesta de marxismo-leninismo-maoísmo es visible en las apreciaciones de Sendero, que rescatan el examen de Mariátegui sobre la realidad peruana para ajustar la teoría revolucionaria de Mao a las condiciones coloniales y feudales vigentes en Perú. Al mismo tiempo, la revolución en el país andino está sometida a dos etapas -democrática y socialista- subrayadas por Mariátegui en la fundación del Partido Comunista. La primera fase exige la pugna con las fuerzas reaccionarias -imperialistas y feudalistaspara interponer una guerra popular a través de la lucha armada destinada a cercar los núcleos urbanos desde el medio rural. El sujeto revolucionario es el campesinado bajo la batuta del Partido Comunista y la violencia congénita de los procesos revolucionarios representa la médula del marxismo. En consecuencia, Sendero establece que su compromiso con este ideario impone la necesidad de embarcarse en la lucha armada (PCP-SL, 1979).

El Partido Comunista no impide la colonización del poder político por parte de las oligarquías. La clase obrera muestra su incapacidad de doblegar la dominación imperialista y de eliminar la pervivencia del feudalismo porque, precisamente, la revolución democrática no ha sido impulsada mediante el recurso de la violencia armada (PCP-SL, 1979). Sendero Luminoso insiste en estimular la protesta popular a través de la lucha promovida desde las armas. En líneas generales, la organización senderista sostiene que su estrategia de recurrir a la lucha armada es respaldada por numerosas figuras revolucionarias y por algunos grupos populares, aunque las argumentaciones manifestadas en ambos casos desdeñan la viabilidad del conflicto e invocan a las condiciones subjetivas de Perú. Sin embargo, Sendero Luminoso considera el escenario favorable para estimular la movilización de las masas y recurre a los análisis elaborados por Lenin sobre las manifestaciones huelguísticas de la clase obrera en el contexto de la Revolución de 1917. 
La sociedad peruana atestigua la crisis e ingresa en un período trascendental, según la percepción senderista, mientras las formaciones políticas buscan asentar sus posiciones para marcar el rumbo de sus futuras acciones. El análisis de la organización encabezada por Guzmán considera oportuno, en estas circunstancias, la actualización de los análisis relativos a la situación socioeconómica del país andino para motivar la trayectoria establecida por Mariátegui y que culmina en la meta revolucionaria (PCP-SL, 1978). La agencia estatal, la violencia y el procedimiento electoral captan la atención de PCP, que interpreta el Estado como una dictadura de terratenientes feudales y grandes burgueses al servicio del imperialismo estadounidense bajo el disfraz de un modelo representativo. Las razones de su pervivencia radican en el ejercicio de los sistemas coercitivos -iniciativas militares antiguerrilleras, estados de excepción, encarcelamientos, persecuciones, suspensión de garantías, etc.para sostener en el poder a las clases explotadoras.

La violencia jalona la historia de Perú y desprende una dimensión dialéctica mediante la contraposición del colonialismo español y los insurgentes dirigidos por Tupac Amaru. Sin embargo, Sendero Luminoso sostiene que el surgimiento del proletariado ofrece un salto cualitativo en la idea de la violencia revolucionaria y su especificidad es visible en la conflictividad campesina abanderada por el Partido Comunista en su afán de cercar las ciudades (PCP-SL, 1978). La derrota sufrida por la "heroica guerrilla" en 1965 no niega, sin embargo, la efectividad de la guerra popular prolongada enunciada por Mao y tampoco borra las huellas del camino trazado por Mariátegui, sino que demandan el compromiso de imponer el mando de la línea política del Partido (PCP-SL, 1978).

La sustancia retórica de Sendero Luminoso reside en "la glorificación de la violencia" (Portocarrero, 2015: 24). La eficacia de la narrativa senderista está provocada por el perfil intelectual de las figuras que integran la cúpula de la organización, que logran enmascarar el componente irracional de sus discursos a través de las constantes referencias teóricas y que inspiran una construcción ideológica específica (Portocarrero, 2015).

El carácter maoísta de Sendero añade una nueva línea a los inconvenientes planteados por la insurgencia armada, ya que la Reforma Agraria desarrollada por la dictadura militar logra difuminar la condición semifeudal diagnosticada por Mariátegui. En la escala global, el fallecimiento de Mao y la derrota de su línea continuista frena la Revolución Cultural que alimenta el imaginario senderista (Degregori, 2000). Sin embargo, el PCP-SL niega las nuevas realidades y declina el protagonismo de las potenciales movilizaciones de masas, puesto que la acción colectiva permanece restringida a las decisiones adoptadas por la jerarquía partidista y el predominio de la política adquiere un papel secundario en el proceso revolucionario porque "la violencia es la esencia de la revolución" (Degregori, 2000: 498). 
Portocarrero (2015) argumenta que la violencia política es una expresión desmarcada de comportamientos instintivos y sostiene que su manifestación proviene de los impulsos agresivos individuales potenciados por las frustraciones derivadas de condiciones estructurales, tales como la pobreza o la injusticia. El conjunto de agravios es encauzado mediante determinadas ideologías y organizaciones que suscriben la posibilidad de cambio efectivo a través del recurso a la violencia.

El examen hermenéutico muestra la intersección de tres ideas que engloban la imagen violenta de la revolución senderista manifestada en la década de 1980: culto a la muerte, abolición del ego y exaltación de la figura del líder (Degregori, 200). En el discurso senderista, la idea legitimadora de la fertilidad violencia en el proceso revolucionario es exhibida como categoría científica y su riqueza no procede exclusivamente de "su utilidad para destruir el viejo orden, sino también por su importancia para establecer la sociedad del futuro" (Portocarrero, 2015: 26). De este modo, el papel violento entronca con la concepción marxista que destaca su relevancia entre los factores fundamentales que propician la acumulación originaria, explícita en el Libro I de El Capital, para concluir que "la violencia es la partera de toda vieja sociedad en cuya entraña palpita la vida de otra nueva. Ella misma, la violencia, es una potencia económica" (Marx, 2014: 1297).

El culto a la muerte es exacerbado a medida que progresa la guerra popular e introduce un sustento para las pretensiones maximalistas de Sendero mediante la imagen evocadora anclada en la tanatofilia (Ríos, 2018). Guzmán señala, en el IV Pleno del Comité Central del PCP-SL celebrado en mayo de 1981, la exigencia de tributar una "cuota de sangre" necesaria para el triunfo revolucionario (Degregori, 2000).

La militancia senderista adquiere un compromiso de lucha que implica el sacrificio vital al servicio de la revolución (Gorriti, 1990; Degregori, 2000). La lógica del culto a la muerte inspira el planteamiento de un "equilibrio estratégico" que conduce a la afirmación de la "conveniencia de un genocidio" (Degregori, 2012: 87; Guzmán, 1988). Sendero afirma que el coste del triunfo revolucionario exige "un millón de muertos" (Degregori, 2012: 25).

Guzmán sostiene que la militancia senderista exige liquidar la individualidad para su incorporación a una maquinaria de guerra $\mathrm{y}$, en consecuencia, la disposición de admitir el tributo de una "cuota" de sangre como condición fundamental para el ensanchamiento de la organización (PCP-SL, 1979). El concepto de "cuota" transforma a los militantes en guerreros (Gorriti, 1990: 157-169; Rénique, 2003: 70). En definitiva, la revolución consiste en "un acto de violencia mediante el cual una clase derroca a otra" (Tse-Tung, 1968c: 25).

El culto a la muerte comporta la negación de la individualidad y es interpretado como un mecanismo ineludible en la revolución triunfante. El 
lenguaje senderista introduce numerosos recursos literarios para dotar de épica a su narrativa insurgente y transformar la meta revolucionaria en un dogmatismo teleológico. En esta dirección, el pensamiento-guía sufre una transformación que desemboca en el llamado "pensamiento-Gonzalo" y, en esta metamorfosis, las referencias a Mariátegui son desplazadas y desaparecen progresivamente para entronizar la figura del líder en la categoría de "cuarta espada del marxismo" (Degregori, 2000). El denominado "pensamiento Gonzalo" agrega interpretaciones específicas al maoísmo y una de ellas consiste en declarar la necesidad de militarizar el Partido. Esta idea define la organización del proceso revolucionario en términos bélicos y fundamenta, al mismo tiempo, un "plan estratégico de militarización del partido" (Manrique, 2007: 14-15)

La interpretación radical del maoísmo naturaliza la violencia y el conflicto entraña una dinámica dominado por la disputa antagónica, que es superada a través de la muerte o de la sumisión de una de las partes involucradas en el conflicto. La guerra es, por tanto, el epicentro de la política y simboliza el motor histórico. Por este motivo, el juego parlamentario canalizado mediante la competición electoral constituye una demora en el proceso revolucionario que integra el imaginario senderista (Portocarrero, 2015:).

La exigencia de liquidar la individualidad está resumida en el lema senderista: "El Partido tiene mil ojos y mil oídos" (Degregori, 2012: 94). El rechazo al individualismo manifestado en el compromiso de una firme militancia senderista está fundado en dos motivos: por un lado, el mandato moral que conecta con la exaltación de la solidaridad inoculada por la doctrina católica y, por otro, la limitación impuesta por la actitud individualista en un entorno dominado por la desigualdad y la pobreza (Portocarrero, 2015).

La violencia política desarrollada por Sendero mantiene su continuidad con las sucesivas ofensivas detectadas entre los años 1982-1983. El encadenamiento de sus acciones enlaza con la propuesta teórica de desplegar una guerra popular prolongada. Esta etapa representa la fase más sangrienta del conflicto porque incluye la contraofensiva de las Fuerzas Armadas y las réplicas senderistas (Manrique, 2007).

\section{Consideraciones finales}

Sendero Luminoso recurre a Mariátegui como fuente legitimadora para sus propósitos insurgentes. La reactivación de la retórica reivindicadora de la lucha armada aprovecha las derivas ideológicas propiciadas por las discusiones teóricas y los debates intelectuales registrados entre las décadas de 1940-1960. El senderismo busca extrapolar la situación socioeconómica del país andino según los diagnósticos mariateguianos y, de inmediato, sus elites acomodan 
el discurso a la particular lectura del maoísmo para vertebrar sus ideas revolucionarias en Perú.

La herencia del pensamiento de Mariátegui es fugaz en la configuración ideológica de Sendero Luminoso. Las alusiones al pensamiento del amauta en el dogmatismo de Sendero son, sin embargo, reducidas a una serie de reiteraciones superficiales. El predominio maoísta desplaza el protagonismo de Mariátegui para nutrir las ideas de la organización senderista, que culmina en un cuerpo doctrinal denominado pensamiento-guía y que será conocido como "pensamiento Gonzalo" para destacar dos cuestiones: el peso específico del liderazgo intelectual de Abimael Guzmán en la estrategia insurreccional de Sendero y la originalidad de sus aportaciones con respecto al resto de las fuentes ideológicas. La rúbrica de la lucha de clases describe, en el imaginario senderista, una trayectoria creciente y debe estar auxiliada por la lucha armada.

El reconocimiento de una situación revolucionaria en curso exige abrazar la perspectiva de la lucha de clases y el análisis imbricado en la tensión producida por el binomio revolución-contrarrevolución. El dilema precisa de la valoración de desgranar los dos caminos existentes dentro de una situación objetiva: la senda reaccionaria-burocrática capitaneada por las oligarquías o la apuesta democrática abanderada por las clases populares bajo la dirección de la vanguardia proletaria.

En definitiva, la organización encabezada por Abimael Guzmán comparte los diagnósticos elaborados por Mariátegui relativos a la realidad peruana. En cambio, la radicalización de Sendero Luminoso procede del acomodo de las tesis maoístas a la particular lectura senderista de la coyuntura histórica del país andino. Su culminación es la apuesta inflexible por la lucha armada en el contexto definido por la transición hacia la democracia a comienzos de la década de 1980 .

\section{Referencias bibliográficas:}

Degregori, Carlos Iván, "Discurso y violencia política en Sendero Luminoso", Bulletin de l'Institut français d'études andines, 29 (3), pp. 493-513, 2000. Degregori, Carlos Iván, El surgimiento de Sendero Luminoso. Ayacucho, 19691979: del movimiento por la gratuidad de la enseñanza al inicio de la lucha armada. Lima, Instituto de Estudios Peruanos, 2011.

Degregori, Carlos Iván, How difficult it is to be God. Shining Path's Politics of War in Peru, 1980-1999. Madison: The University of Wisconsin Press, 2012. 
Degregori, Carlos Iván, Sendero Luminoso: I. Los hondos y mortales desencuentros, II. Lucha armada y utopía autoritaria. Documentos de trabajo No. 4 y 6. IEP: Lima, 1985.

Flores Galindo, Alberto, La agonía de Mariátegui. La polémica con la Komintern. Lima: Centro de Estudios y Promoción del Desarrollo, 1980.

Gorriti, Gustavo, Sendero. Historia de la guerra milenaria en el Perú. Lima: Editorial Apoyo, 1990.

Guzmán, Abimael, "Entrevista al Presidente Gonzalo”. El Diario, julio de 1988. Disponible en: http://www.solrojo.org/pcp_doc/pcp_0688.htm [Acceso 9-3-2020].

Krujit, Dirk y Koonings, Kees, "Introducción: la violencia y el miedo en América Latina”. En Kees Koonings y Dirk Krujit (eds.), Las sociedades del miedo: el legado de la guerra civil, la violencia y el terror en América Latina. Salamanca: Ediciones Universidad de Salamanca, pp. 21-49, 2002. Manrique, Nelson, "Pensamiento, acción y base política del movimiento Sendero Luminoso. La guerra y las primeras respuestas de los comuneros (19641983), en Anne Pérotin-Dumon (dir.), Historizar el pasado vivo de América Latina, 2007. Disponible en: https://www.verdadyreconciliacionperu. com/admin/files/articulos/273_digitalizacion.pdf [Consultado el 13-022020].

Mariátegui, José Carlos, "El $1^{\circ}$ de mayo y el frente único", El Obrero Textil, año 5, núm. 59, 1 de mayo 1924.

Mariátegui, José Carlos, Ideología y Política. Y otros escritos. Caracas: El perro y la rana, 2010.

Mariátegui, José Carlos, 7 Ensayos de interpretación de la realidad peruana. Caracas: Fundación Biblioteca Ayacucho, (2007) [1928].

Marx, Karl y Engels, Friedrich. Manifiesto comunista. Madrid, Akal, 1997 [1848].

Marx, Karl, El Capital. Tomo I, Libro I. El proceso de producción del capital. México: Fondo de Cultura Económica, 2014 [1867].

PCP-SL, Comenzamos a derrumbar los muros y a desplegar la aurora, 28 de marzo de 1980.

PCP-SL, Desarrollemos la creciente protesta popular, 1 de septiembre de 1979

PCP-SL, Contra las ilusiones constitucionales y por el estado de nueva democracia, 1 de abril de 1978 .

PCP-SL, Ser marxista es adherir al marxismo-leninismo el pensamiento de Mao Tse-Tung, 1 de octubre de 1977.

PCP-SL, Retomemos a Mariátegui y reconstituyamos su partido. 1 de octubre de 1975. 
Portocarrero, Gonzalo, Razones de sangre. Aproximaciones a la violencia politica. Lima: Fondo Editorial de la Pontificia Universidad Católica del Perú, 2015.

Quijano, Aníbal, Cuestiones y Horizontes. De la Dependencia HistóricoEstrutuctural a la Colonialidad/Descolonialidad del Poder. Buenos Aires: CLACSO, 2014.

Quijano, Aníbal, "Prólogo. José Carlos Mariátegui: reencuentro y debate". En Mariátegui, José Carlos, 7 Ensayos de interpretación de la realidad peruana. Caracas, Fundación Biblioteca Ayacucho, 2007 [1928].

Rénique, José Luis, La voluntad encarcelada: las 'luminosas trincheras de combate' de Sendero Luminoso del Perú. Lima: Instituto de Estudios Peruanos, 2003.

Ríos, Jerónimo, "Narratives about political violence and reconciliation", Latin American Perspectives, 46(5), 2019, pp. 44-58.

Ríos, Jerónimo, "Sendero Luminoso: Una apología de la violencia", Revista de Cultura de Paz, 2, 2018, pp. 277-294.

Ríos, Jerónimo y Sánchez, Marté, Breve historia de Sendero Luminoso. Lima: Revuelta Editores - La Catarata, 2018.

Tse-Tung, Mao, "La situación actual y nuestras tareas". En Obras escogidas. Tomo IV: Período de la tercera guerra civil revolucionaria. Pekín: Ediciones en Lenguas Extranjeras, 1976.

Tse-Tung, Mao, "Una sola chispa puede incendiar la pradera", en Obras escogidas. Tomo I: Período de la primera guerra civil revolucionaria. Pekín: Ediciones en Lenguas Extranjeras, 1968a.

Tse-Tung, Mao, "Problemas estratégicos de la guerra revolucionaria de China" en Obras escogidas. Tomo I: Período de la primera guerra civil revolucionaria. Pekín: Ediciones en Lenguas Extranjeras, 1968b.

Tse-Tung, Mao, "Informe sobre una investigación del movimiento campesino en Junan", en Obras escogidas. Tomo I: Período de la primera guerra civil revolucionaria. Pekín: Ediciones en Lenguas Extranjeras, 1968c. 
